\title{
Comparative proteomics reveal negative effects of gonadotropin-releasing hormone agonist and antagonist on human endometrium
}

This article was published in the following Dove Press journal:

Drug Design, Development and Therapy

\author{
Qian Chen ${ }^{1} *$ \\ Feng $\mathrm{Yu}^{2, *}$ \\ Yan $\mathrm{Li}^{1}$ \\ Ai-Jun Zhang' \\ Xiao-Bin Zhu' \\ 'Center of Reproductive Medicine, Ruijin \\ Hospital, Shanghai Jiao Tong University \\ School of Medicine, Shanghai, People's \\ Republic of China; ${ }^{2}$ Interdisciplinary \\ Science Research Institute, Shanghai \\ University of Traditional Chinese \\ Medicine, Shanghai, People's Republic of \\ China \\ *These authors contributed equally to \\ this work
}

Correspondence: Xiao-Bin Zhu; Ai-Jun Zhang

Center of Reproductive Medicine, Ruijin

Hospital, Shanghai Jiao Tong University

School of Medicine, 197 Rui-jin 2nd Road,

Shanghai 200025, People's Republic of China

Tel +862164370045

Email cliff26@।26.com; zhaj I268@।63.com
Purpose: The two major ovarian-stimulation protocols for in vitro fertilization are gonadotropin-releasing hormone agonist (GnRH-a) protocol or GnRH antagonist (GnRH-ant) protocol; however, comparisons of their relative efficacy remain controversial. Additionally, conflicting data exist regarding their effects on endometrial receptivity. Thus, this study investigated how GnRH-a and GnRH-ant treatments alter the endometrium during the midsecretory phase.

Patients and methods: We compared proteomic profiles across human endometrium tissues of mid-secretory phase from normal control humans $(n=5)$, patients treated with GnRH-a ( $n=5)$, and patients treated with GnRH-ant ( $n=5)$.

Results: We identified 2088 proteins, with 362 that exhibited significantly different expression. Fuzzy c-means clustering (FCM) using the M Fuzz algorithm analysis showed that the same 87 proteins changed significantly in both the GnRH-a and GnRH-ant groups compared with those in the control. Moreover, Gene Ontology (GO) analysis showed that, of these 87, downregulated proteins were associated with energy metabolism and upregulated proteins were linked to cytoskeleton maintenance. Upregulated proteins involved in complementmediated immunity were present in 151 proteins that exhibited significantly different expression in the GnRH-ant group only.

Conclusion: We demonstrated that comparative proteomic analysis is useful for accessing endometrial receptivity, which seemed more strongly impaired by GnRH-ant than GnRH-a treatments. Our findings also revealed that energy metabolism and immunity response may be the key biological mechanisms underlying human endometrial receptivity.

Keywords: endometrial receptivity, proteomic profile, energy metabolism, complementmediated immunity

\section{Introduction}

Infertility is a condition with complex etiology that has become increasingly common worldwide. Approximately $6-15 \%$ of Chinese couples experience difficulties conceiving, leading to familial and social problems. To improve existing infertility treatments, we require a thorough understanding of how assisted reproductive technology (ART), especially in vitro fertilization (IVF), functions mechanistically in humans. Despite increasing efficiency in oocyte retrieval and fertilization techniques, live birth rates of IVF remain less than $45 \%$ per oocyte retrieval cycle. ${ }^{1}$ Ovulation stimulation can improve IVF success through inducing the development of multiple follicles. However, the growth of multiple follicles 
may also cause premature onset of endogenous luteinizing hormone $(\mathrm{LH})$ peak. The premature $\mathrm{LH}$ rise due to the positive feedback triggered by high serum estrogen levels in the midfollicular phase can lead to oocyte maturation arrest and cyclecancellation, thereby compromising IVF outcomes. $^{2}$

Currently, the two most common protocols for ovarian stimulation are GnRH-a (gonadotropin-releasing-hormone agonist) and GnRH-ant (GnRH antagonist) treatments, both of which prevent premature LH spikes in most women. ${ }^{3}$ In particular, during controlled ovarian hyperstimulation $(\mathrm{COH}), \mathrm{GnRH}-a n t$ can inhibit the LH surge without the side-effects (flare-ups, hypo-estrogenic, long down-regulation period) associated with agonists. ${ }^{4}$ Through competitive binding to pituitary GnRH receptors, GnRH-ant directly inhibits gonadotrophin and steroid hormone release within several hours of administration.

Both GnRH-a and GnRH-ant may have negative effects on endometrial receptivity when used in $\mathrm{COH}^{5-7}$ Although it is still controversial, a considerable number of studies and meta-analysis suggest that the pregnancy and implantation rate of fresh transfer cycles is lower in the GnRH-ant protocol than in the GnRH-a protocol, ${ }^{8-10}$ and this may be related to endometrial receptivity. ${ }^{11-14}$ However, we do not fully understand the mechanisms that impair endometrial receptivity following GnRH-ant treatment. Research in mice has suggested a potential epigenetic mechanism. Specifically, the influence of GnRHant on Hoxa10 methylation status appears to affect uterine receptivity, downregulating endometrial integrin $\beta 3$ expression and suppressing pinopode development. ${ }^{15}$ These findings may explain the low implantation rate in GnRH-ant treatments at IVF clinics.

Given the questions that remain regarding negative effects on the endometrium and embryo implantation, appropriate dose regimens and clinical usage must still be determined before GnRH-ant can be considered a reliable ovarian stimulation method. In this study, we sought to understand the effects of GnRH-a and GnRH-ant treatment through proteomic analyses on endometrium tissue from the mid-secretory phase.

\section{Material and methods}

\section{Subjects}

This study was conducted in accordance with the Declaration of Helsinki. The Institutional Ethics Committee of Ruijin Hospital, Shanghai Jiao Tong
University School of Medicine, approved all tissue collections. Written informed consent was obtained from every participant. The study recruited women (26-32 years old) who were receiving IVF treatment for tubal obstruction at the Reproductive Medical Center of Ruijin Hospital. Patients were excluded if they presented significant intrauterine or ovarian abnormalities by transvaginal ultrasonography and laparoscopy (eg, endometrial polyps, leiomyomas, adenomyosis, endometriosis) or received steroid hormone therapy in the last 3 months. Furthermore, women were only included in data analyses if they became pregnant after frozen embryo transfer (FET) treatments with natural cycle post-endometriumsampling.

\section{Human endometrial tissue biopsy}

Our experimental design followed the previously established guidelines for collecting endometrial samples. ${ }^{16}$ Samples were obtained from women at their mid-secretory phase (control, post-ovulation day 7, n=5; GnRH-ant and GnRH-a, day 7 post-oocyte retrieval, $n=5$ each; Figure 1, Table 1), using a single-use $\mathrm{S}$ type endometrial biopsy tube (TY-C3.1/30-1S, TianYi, Zhejiang, China). Samples were washed immediately in saline to remove blood and then frozen in liquid nitrogen until further use.

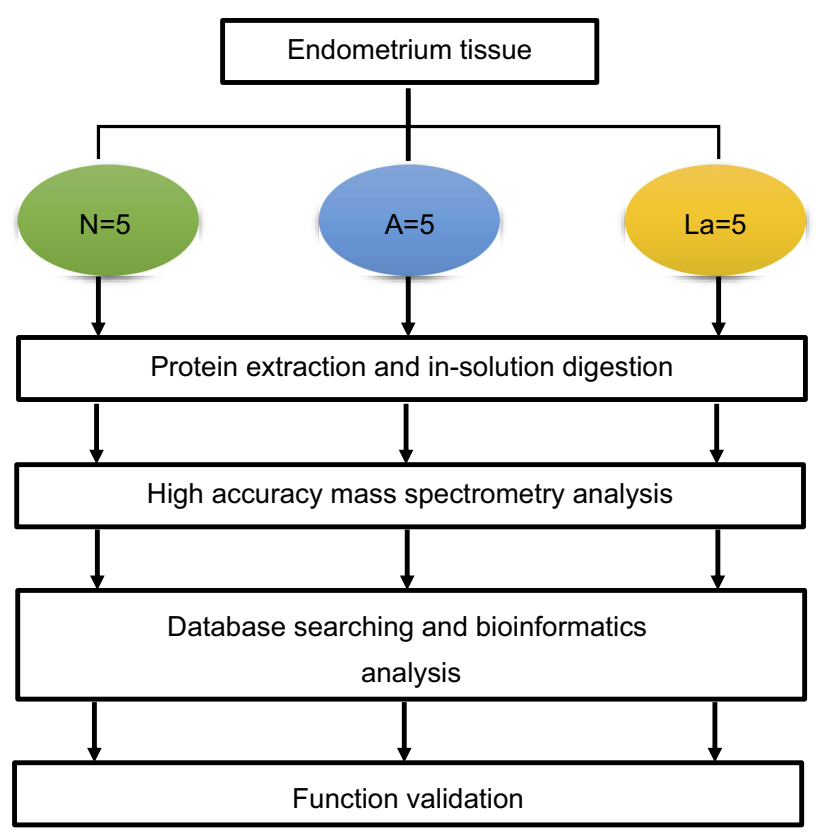

Figure I Flowchart of the label-free quantitative proteomic analysis of endometrial tissues.

Abbreviations: N, normal control; $\mathrm{A}, \mathrm{GnRH}$ antagonist-treated group ( $\mathrm{GnRH}$-ant); $\mathrm{La}, \mathrm{GnRH}$ agonist-treated group $(\mathrm{GnRH}-\mathrm{a})$. 
Table I Patient clinical parameters. Demographic characteristics did not differ across subjects in the three groups

\begin{tabular}{|c|c|c|c|c|}
\hline & $\begin{array}{l}N \text { group } \\
(n=5)\end{array}$ & $\begin{array}{l}\text { A group } \\
(n=5)\end{array}$ & $\begin{array}{l}\text { La } \\
\text { grou- } \\
\text { p } \\
(n=5)\end{array}$ & $P$-value \\
\hline Age (years) & $29.4 \pm 2.3$ & $28.6 \pm 2.7$ & $\begin{array}{l}29.4 \\
\pm 2.1\end{array}$ & 0.806 \\
\hline BMI & $21.0 \pm 1.2$ & $20.7 \pm 1.5$ & $\begin{array}{l}20.1 \\
\pm 1.1\end{array}$ & 0.575 \\
\hline $\mathrm{bFSH}(\mathrm{mlU} / \mathrm{mL})$ & $6.8 \pm 0.9$ & $6.9 \pm 1.2$ & $6.7 \pm 1.4$ & 0.938 \\
\hline bLH (mlU/mL) & $4.4 \pm 1.1$ & $5.6 \pm 1.2$ & $5.7 \pm 0.8$ & 0.212 \\
\hline $\mathrm{bE}_{2}(\mathrm{pg} / \mathrm{mL})$ & $45.6 \pm 6.4$ & $54.2 \pm 7.0$ & $\begin{array}{l}47.2 \\
\pm 5.8\end{array}$ & 0.173 \\
\hline $\begin{array}{l}\text { Dosage of gona- } \\
\text { dotrophin (IU) }\end{array}$ & - & $\begin{array}{l}I, 755.0 \\
\pm 253.7\end{array}$ & $\begin{array}{l}I, 792.5 \\
\pm 220.5\end{array}$ & 0.829 \\
\hline $\begin{array}{l}\text { Duration of sti- } \\
\text { mulation (days) }\end{array}$ & - & $9.6 \pm 0.8$ & $\begin{array}{l}10.2 \\
\pm 0.8\end{array}$ & 0.305 \\
\hline $\begin{array}{l}\text { No. of oocytes } \\
\text { retrieved }\end{array}$ & - & $17.0 \pm 2.6$ & $\begin{array}{l}17.8 \\
\pm 2.6\end{array}$ & 0.673 \\
\hline $\begin{array}{l}E_{2} \text { on day of } H C G \\
\text { injection }(p g / m L)\end{array}$ & - & $8,26 I \pm 573$ & $\begin{array}{l}8,188 \\
\pm 672\end{array}$ & 0.873 \\
\hline $\begin{array}{l}P \text { on day of HCG } \\
\text { injection }(\mathrm{ng} / \mathrm{mL})\end{array}$ & - & $1.02 \pm 0.16$ & $\begin{array}{l}0.96 \\
\pm 0.28\end{array}$ & 0.690 \\
\hline $\begin{array}{l}\text { Peak pre- } \\
\text { ovulation endo- } \\
\text { metrial thickness } \\
(\mathrm{mm})\end{array}$ & $8.8 \pm 0.8$ & $9.8 \pm 0.8$ & $9.0 \pm 0.6$ & 0.152 \\
\hline
\end{tabular}

Notes: The results are represented as mean \pm SD. $P<0.05$ was considered statistically significant.

Abbreviations: $\mathrm{N}$, normal control; $\mathrm{A}, \mathrm{GnRH}$ antagonist-treated group $(\mathrm{GnRH}$ ant); La, GnRH agonist-treated group ( $\mathrm{GnRH}$-a); BMI, body mass index; FSH, follicle stimulating hormone; LH, Luteinizing hormone; $\mathrm{E}_{2}$, Estradiol; HCG, human chorionic gonadotropin; P, progesterone; IU, International unit.

In the control group, ultrasonography was performed every other day from days 7-9 of the menstrual cycle until dominant follicle diameter was $>15 \mathrm{~mm}$. Subsequently, ultrasonography was performed daily and serum $\mathrm{LH}$ and $\mathrm{E}_{2}$ were quantified daily using a chemoluminescence technique (Beckman) until follicular rupture. Endometrial samples were collected 7 d post-ovulation and progesterone levels were quantified the same day. Appropriate ovulation was confirmed by LH levels of more than $20 \mathrm{mIU} / \mathrm{ml}$ and sampling day progesterone levels of $>8 \mathrm{ng} / \mathrm{ml}^{17}$

In the GnRH-a group, $0.1 \mathrm{mg}$ GnRH-a (Triptorelin Acetate, Ferring, Germany) was administered subcutaneously daily in the mid-luteal phase of the preceding cycle to induce pituitary downregulation. When suppressive effects $\left(E_{2}<50 \mathrm{pg} / \mathrm{mL}\right.$, no cysts or ultrasound follicles with maximum diameter $>1.0 \mathrm{~cm}$ ) were observed, $150-300 \mathrm{IU}$ of
rFSH (Gonal-F, Merck Serono, Germany) was administered daily to stimulate ovaries. Simultaneously, GnRH-a was reduced to $0.05 \mathrm{mg} / \mathrm{d}$ until hCG administration.

In the GnRH-ant group, 150-300 IU of rFSH was injected subcutaneously when $\mathrm{E}_{2}<80 \mathrm{pg} / \mathrm{mL}$ and no ultrasound follicles with maximum diameter $>1.0 \mathrm{~cm}$ was detected (on day 3 of menstrual cycle). On day 6, or when at least one follicle was $\geq 14 \mathrm{~mm}, 0.25 \mathrm{mg} \mathrm{GnRH}-$ ant (Cetrotide; Merck Serono, Germany) was subcutaneously administered daily until hCG administration.

In both the GnRH-a and GnRH-ant groups, initial stimulation doses were adjusted based on follicular growth and $E_{2}$ levels, and progesterone levels were also monitored. When at least two follicles measured $>18 \mathrm{~mm}$ in diameter, 5000 IU of hCG (LiZhu, China) was administered. Transvaginal ultrasound-guided follicle aspiration retrieved oocytes at $36 \mathrm{~h}$ after hCG administration. Patients with all embryos frozen for preventing ovarian hyperstimulation syndrome (OHSS) were included in the experiment. Luteal support was administered right after oocyte retrieval until endometrial collection.

\section{Protein extraction and trypsin digestion using FASP}

Endometrial tissues were lysed in $0.1 \mathrm{M}$ Tris- $\mathrm{HCl}(\mathrm{pH}$ 7.6) containing $50 \mathrm{mM}$ DTT and $2 \%$ SDS (w/v), placed in a boiling water bath for $4 \mathrm{~min}$. After cooling to room temperature, lysates were centrifuged at $16,000 \times \mathrm{g}$ for $10 \mathrm{~min}$, then processed following the MED-FASP protocol with trypsin. ${ }^{18}$ Total protein and total peptide content were determined using a tryptophan-fluorescence assay. ${ }^{19}$

\section{Mass spectrometry}

Peptides were separated on a reverse phase column (13.5 $\mathrm{cm} \times 75 \mu \mathrm{m}$ inner diameter) packed with $1.8 \mu \mathrm{m}$ C18 particles (Dr. Maisch GmbH, AmmerbuchEntringen, Germany). A $4 \mathrm{~h}$ acetonitrile gradient in $0.1 \%$ formic acid was used, at a flow rate of $250 \mathrm{~nL} / \mathrm{min}$. Liquid chromatography was coupled to a $\mathrm{Q}$ Exactive mass spectrometer (Thermo Fisher Scientific, Germany) via a nanoelectrospray source (Proxeon Biosystems, now Thermo Fisher Scientific). Survey scans were acquired at a resolution of 60,000 at $\mathrm{m} / \mathrm{z} 400$ (transient time $256 \mathrm{~ms}$ ) in the data-dependent mode. The top 10 most abundant isotope patterns with charge $\geq+2$ were selected with an isolation window of $2.0 \mathrm{Th}$. Isotopes were then fragmented using HCD, with normalized collision energies of 25 . 
Maximum ion injection times for survey scans and MS/ MS scans were $20 \mathrm{~ms}$ and $60 \mathrm{~ms}$, respectively.

\section{Data analysis}

Raw data were analyzed in MaxQuant (http://maxquant. org/, version 1.3.0.5 $)^{20}$ using the International Protein Index (IPI) (version 3.87, 91464 protein sequences; European Bioinformatics Institute). Carbamidomethyl (C) was set as a fixed modification, while protein N-terminal acetylation and oxidation $(\mathrm{M},+15.99492$ $\mathrm{Da})$ was set as a variable modification. Trypsin/P was selected as the digestive enzyme with two potential missed cleavages. The Andromeda search engine controlled false discovery rate (FDR) for peptides and protein groups to $<1 \%{ }^{21}$ The number of reverse hits divided by the number of forward hits yielded FDR. $^{21,22}$ Label-free quantification was performed in MaxQuant using intensity determination and normalization algorithms. ${ }^{23}$ Intensities of different isotopic peaks for a given peptide were summed; only peptides that could be assigned to a protein unambiguously were used for further analysis. ${ }^{23}$ To correct for unequal sample mixing, LFQ intensities were first normalized to a median ratio of 1 . Ratios were $\log 2$-transformed to yield a roughly normal distribution. ${ }^{24}$

\section{Statistical analysis}

Patient clinical parameters were analyzed using SPSS (Version 16.0, SPSS Inc.). One-way analysis of variance (ANOVA) was used to compare three groups, and Student's $t$-test was used to compare two groups. Functional and pathway-enrichment analyses were performed in DAVID (https://david.ncifcrf.gov/). Significance was set at $P<0.05$. Pathway enrichment was assessed with a hypergeometric distribution.

\section{Results}

\section{Sample analysis}

We identified 2,088 proteins in 15 samples based on $1 \%$ protein and peptide FDR (Table S1). Normalized protein expression per sample revealed similarly shaped distributions (Figure S1). Correlation analyses revealed high reliability of label-free quantitative proteomics, as two duplicates of one endometrial sample were highly correlated in protein abundance (Figure S2).

\section{Differences between control and}

\section{treatment proteomes}

Of the 2,088 proteins analyzed, 362 (17.34\%) differed significantly in abundance between control, GnRH-a, and GnRH-ant groups (ANOVA, $P<0.05$; Table S1). Hierarchical clustering analysis (HCA) and principal component analysis (PCA) revealed three distinct profiles corresponding to the experimental groups, with the control being noticeably separated from GnRH-a and GnRH-ant (Figure 2A and B).

\section{Screening for related biomarkers}

We used two criteria to characterize biomarkers that differed significantly between GnRH-a and GnRH-ant. First, candidate protein abundance should differ significantly between control and GnRH-a $(P \leq 0.05)$, but not between control and GnRH-ant $(P>0.05)$. Second, abundance should differ significantly between normal and GnRH-ant $(P \leq 0.05)$, but not between control and GnRH-a $(P>0.05)$. The cutoffs for fold changes (FC) in abundance were 1.3 and 0.77 . Between control and GnRH-ant groups, we found 151 differentially abundant proteins (Figure 2C; Table S3), along with 124 significantly different proteins between control and GnRH-a (Figure 2C; Table S4). Furthermore, 87 proteins differing significantly from control were common across GnRHant and GnRH-a (Figure 2C; Table S2). Figure 2D shows the two-dimensional distribution of $-\log 10 P$-value vs $\log 2 \mathrm{FC}$ ratio for the 362 significantly different proteins.

\section{Similar changes to energy metabolism and cytoskeleton regulation under $\mathrm{GnRH}-\mathrm{a}$ and $\mathrm{GnRH}$-ant}

Fuzzy c-means (FCM) clustering analysis revealed similar proteomic changes between GnRH-a and GnRH-ant treatments (Figure 3), suggesting that the 87 common proteins (Figure $2 \mathrm{C}$ ) exerted overlapping effects on the endometrium. Next, Gene Ontology (GO) analysis ${ }^{25}$ revealed that these proteins highly enriched eight terms under biological processes (BP) (Figure 4A) and nine terms under molecular function (MF) (Figure 4B). Specifically, proteins involved in "Energy metabolism" (under BP) were downregulated in the two treatments compared with control (Figure 4A), whereas proteins involved in "Cell structure and motility," as well as "Extracellular matrix protein-mediated signaling," were 
A

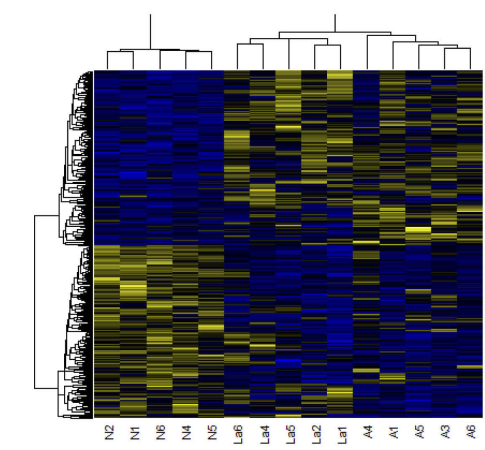

C

151

87

124
B

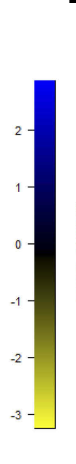

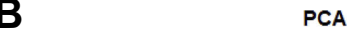

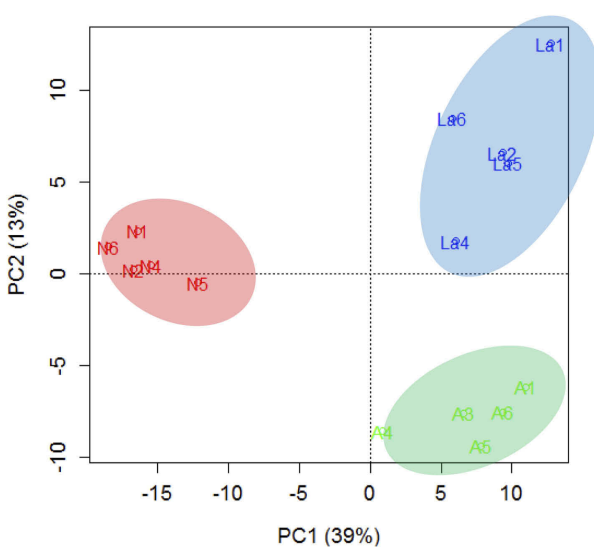

D

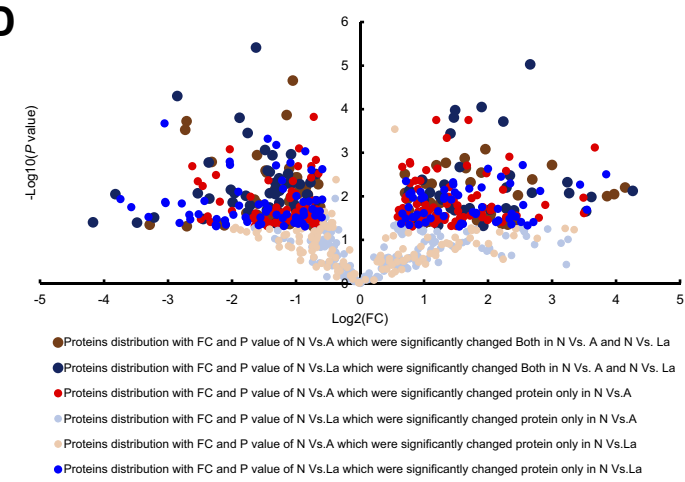

Figure 2 Comparison of significantly changed proteins in endometrial tissues under the three treatment groups. Principal components analysis (A) and hierarchical clustering analysis (B) of 362 significantly changed proteins. We found 87 proteins that changed significantly in $\mathrm{N}$ vs $\mathrm{A}$ and $\mathrm{N}$ vs La. Between $\mathrm{N}$ and $\mathrm{A}$, I5I proteins changed significantly, whereas 124 proteins changed between $\mathrm{N}$ and La. (C) Venn diagram and (D) volcanic map presentation of significantly changed proteins that overlapped across groups.

Abbreviations: N, normal control; $\mathrm{A}, \mathrm{GnRH}$ antagonist-treated group (GnRH-ant); La, GnRH agonist-treated group (GnRH-a); PCA, principal component analysis.

upregulated. Furthermore, proteins involved in "Extracellular matrix" and "Cytoskeletal protein" (under MF) were upregulated under both treatments (Figure 4B), while proteins involved in "Hydrolase" and "Dehydrogenase" were downregulated.

\section{Relationship between complement-mediated immunity and endometrial receptivity under $\mathrm{GnRH}$-ant treatment}

Functional annotation of uniquely differentially expressed proteins under GnRH-a (124 proteins) and GnRH-ant (151) revealed that the former treatment influenced energy metabolism and cytoskeletal regulation (Figure 4E and F). Additionally, only GnRH-ant treatment caused upregulated proteins involved in MHCI-mediated immunity, along with complement and coagulation cascades (Figure 4C and D).

\section{Discussion}

In this study, we identified 362 proteins that differed significantly in abundance between treatment and control $(P<0.05)$, forming three distinct profiles corresponding to the three experimental groups (Figure 2A and B). We identified 87 uniquely expressed proteins as biomarkers for GnRH-a and GnRH-ant treatments. Gene ontology analysis revealed their involvement in many biological processes, suggesting potentially complex mechanisms underlying the effects of GnRH-a and GnRH-ant. Specifically, both are associated with upregulation of cytoskeleton regulation and downregulation of energy metabolism. This outcome is consistent with our previous research. $^{26}$ There, we had suggested that the upregulation of energy metabolism is a major endometrial change during the mid-secretory phase. Therefore, the downregulation of energy-metabolism proteins under GnRH-a and GnRH-ant treatments probably exerted a negative effect on endometrial receptivity, explaining low implantation success. 

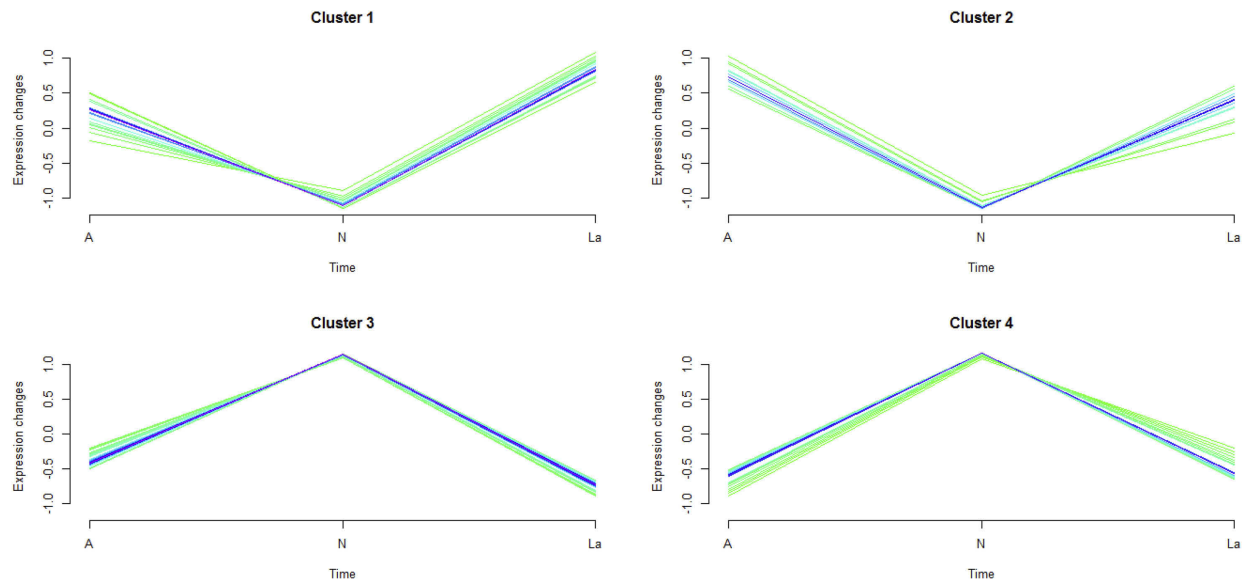

Figure $3 \mathrm{C}$-means clustering analysis of 87 significantly changed proteins common across $\mathrm{N}$ vs $\mathrm{A}$ and $\mathrm{N}$ vs La.

Abbreviations: N, normal control; A, GnRH antagonist-treated group (GnRH-ant); La, GnRH agonist-treated group (GnRH-a).

Further GO analyses revealed that 124 uniquely upregulated proteins under GnRH-a treatment enriched cytoskeletal regulation (Figure 4C and D), while 151 under GnRH-ant treatment enriched complement-mediated immunity (Figure $4 \mathrm{E}$ and $\mathrm{F}$ ). Immune remodeling events in endometrium are vital for pregnancy. Beginning before implantation, these Immune events allow for subsequent maternal immune tolerance and regulate the placentation process. ${ }^{27}$ Disturbance of immune remodeling can result in loss of endometrial receptivity or early pregnancy disorders. ${ }^{28,29}$ Evidence of disrupted immunity only in the GnRH-ant group suggests that GnRH-ant has a stronger negative effect on endometrial receptivity than GnRH-a. Indeed, GnRH-ant (Cetrorelix) has 20 times greater affinity for $\mathrm{GnRH}$ receptors than natural $\mathrm{GnRH}$ and 2 times greater affinity than GnRH-a (Buserelin). ${ }^{30}$ Therefore, despite the low chance of generating biological effects from endogenous GnRH interacting with GnRH receptors outside the pituitary, GnRH-ant is likely still able to directly affect embryo implantation through stronger binding to endometrial cells, ${ }^{31}$ which present GnRH receptors. ${ }^{32}$

Several proteins vital to endometrial function were significantly changed in GnRH-ant group only (Table S3). Immune-response proteins (HLA-B) are important in maternal fetal interface, ${ }^{33}$ while also being linked to endometriosis (the presence of endometrial tissue outside the uterus). ${ }^{34,35}$ This condition causes diverse complications, including infertility, pelvic pain, dysmenorrhea, and constipation. Here, observed changes to HLA-B abundance indicated an abnormal endometrium and impaired receptivity. Alpha-2 macroglobulin (A2M) also varied significantly under GnRH-ant treatment. A broad-spectrum plasma protease inhibitor, $\mathrm{A} 2 \mathrm{M}$ is produced in the human endometrium. ${ }^{36}$
Physiological A2M concentrations inhibit mouse embryo development in vitro, suggesting that endometrial production of this inhibitor regulates preimplantation embryo development. ${ }^{36}$ Moreover, A2M is predominantly produced by the stromal component of endometrial tissue and is menstrual-cycle dependent. Zonal differences in A2M expression within the endometrium may influence implantation, a connection that merits further investigation. ${ }^{37}$

One limitation of our study is that samples were collected from patients who had all embryos frozen for preventing OHSS. These patients had extremely high $\mathrm{E}_{2}$ levels and may not be reflective of the average number of patients undergoing ovarian stimulation. However, Macklon et al performed biopsy of the endometrium in egg donors during the implantation window. ${ }^{38}$ Gene analysis showed that dysregulation of the endometrial transcriptome in the $\mathrm{COH}$ cycle is not fully attributable to supraphysiological estrogen levels. In the current study, patient conditions in the GnRH-ant and GnRH-a groups were very similar. Peak values of estrogen and progesterone levels during ovulation induction were also similar. However, the protein profile was significantly different, suggesting that receptivity change was not simply regulated by the hormone levels. The other limitation of this study is that the sample size was small. Therefore, the current findings should be validated in future studies; for example, overexpression/knockdown studies using in vitro or in vivo models. In addition, signaling pathways of these implantation-related proteins should be further determined, such as the complementmediated immunity pathway. We plan to carry out these experiments in our future research. 

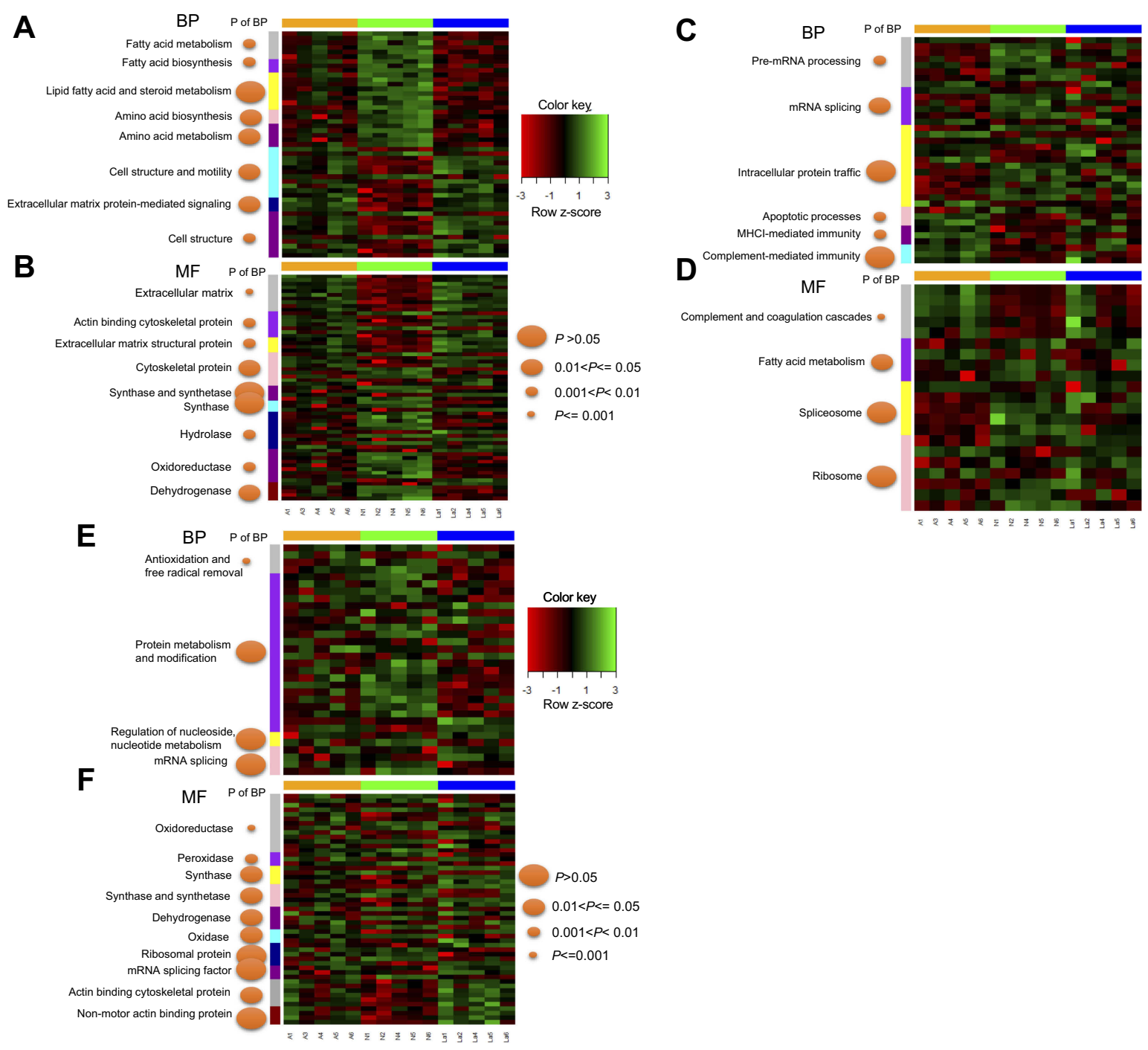

Figure 4 Representation of significantly changed proteins common across $\mathrm{N}$ vs $\mathrm{A}$ and $\mathrm{N}$ vs La. Proteins were assigned to gene ontology terms related to biological process (BP) (A) and MF (B) in DAVID. We identified 87 significantly changed proteins common to $\mathrm{N}$ vs $\mathrm{A}$ and $\mathrm{N}$ vs La. Additionally, I I proteins changed significantly changed only in $\mathrm{N}$ vs $\mathrm{A}$ (C-D); 124 proteins changed only in $\mathrm{N}$ vs La (E-F).

Abbreviations: $\mathrm{N}$, normal control; $\mathrm{A}, \mathrm{GnRH}$ antagonist-treated group (GnRH-ant); La, GnRH agonist-treated group (GnRH-a); BP, biological process; MF, molecular function.

In summary, we characterized distinct protein signatures of normal, GnRH-a-treated, and GnRH-ant-treated endometrial tissues to demonstrate the possible effects of agonists and antagonists. Our observations provide novel evidence for the molecular mechanisms (ie energy metabolism, immune response) underlying endometrial receptivity and therefore should benefit the development of improved ovarian stimulation techniques that minimize implantation failure rates in IVF.

\section{Acknowledgments}

This study was supported by the National Natural Science Foundation of China (grant no. 81671517 and no. 81100469 , to Chen Qian) and Scientific Research Foundation of Shanghai
Municipal Commission of Health and Planning (grant no. 201840060, to Zhu Xiaobin).

\section{Author contributions}

Qian Chen: data collection, manuscript writing. Feng Yu: data analysis. Qian Chen, Li Yan, Ai-Jun Zhang, Xiao-Bin Zhu: protocol/project development. All authors contributed toward data analysis, drafting and revising the paper, gave final approval of the version to be published, and agree to be accountable for all aspects of the work.

\section{Disclosure}

The authors report no conflicts of interest in this work. 


\section{References}

1. Kushnir VA, Darmon SK, Barad DH, Gleicher N. Observational retrospective study of US national utilisation patterns and live birth rates for various ovarian stimulation protocols for in vitro fertilisation. BMJ Open. 2018;8(11):e023124. doi:10.1136/bmjopen2018-023124

2. Stanger JD, Yovich JL. Reduced in-vitro fertilization of human oocytes from patients with raised basal luteinizing hormone levels during the follicular phase. $B r \quad J$ Obstet Gynaecol. 1985;92 (4):385-393. doi:10.1111/j.1471-0528.1985.tb01113.x

3. Orvieto R, Patrizio P. GnRH agonist versus GnRH antagonist in ovarian stimulation: an ongoing debate. Reprod Biomed Online. 2013;26(1):4-8. doi:10.1016/j.rbmo.2012.11.001

4. Devroey P, Aboulghar M, Garcia-Velasco J, et al. Improving the patient's experience of IVF/ICSI: a proposal for an ovarian stimulation protocol with GnRH antagonist co-treatment. Hum Reprod. 2009;24(4):764-774. doi:10.1093/humrep/den468

5. Bourgain C, Devroey P. The endometrium in stimulated cycles for IVF. Hum Reprod Update. 2003;9(6):515-522. doi:10.1093/humupd/dmg045

6. Devroey P, Bourgain C, Macklon NS, Fauser BC. Reproductive biology and IVF: ovarian stimulation and endometrial receptivity. Trends Endocrinol Metab. 2004;15(2):84-90. doi:10.1016/j.tem.2004.01.009

7. Kolibianakis EL, Bourgain C, Albano C, et al. Effect of ovarian stimulation with recombinant follicle-stimulating hormone, gonadotropin releasing hormone antagonists, and human chorionic gonadotropin on endometrial maturation on the day of oocyte pick-up. Fertil Steril. 2002;78(5):1025-1029. doi:10.1016/S0015-0282(02)03323-X

8. Al-Inany HG, Abou-Setta AM, Aboulghar M. Gonadotrophinreleasing hormone antagonists for assisted conception: a Cochrane review. Reprod Biomed Online. 2007;14:640-649. doi:10.1016/ S1472-6483(10)61059-0

9. Lambalk CB, Banga FR, Huirne JA, et al. GnRH antagonist versus long agonist protocols in IVF: a systematic review and meta-analysis accounting for patient type. Hum Reprod Update. 2017;23:560-579. doi:10.1093/humupd/dmx017

10. Xu B, Zhou M, Wang J, et al. Increased AIF-1-mediated TNF- $\alpha$ expression during implantation phase in IVF cycles with $\mathrm{GnRH}$ antagonist protocol. Hum Reprod. 2018;33(7):1270-1280. doi:10.1093/humrep/dey119

11. Bukulmez O, Carr BR, Doody KM, Doody KJ. Serum cetrorelix concentrations do not affect clinical pregnancy outcome in assisted reproduction. Fertil Steril. 2008;89(1):74-83. doi:10.1016/j.fertnstert.2007.02.059

12. Eftekhar M, Dehghani Firouzabadi R, Karimi H, Rahmani E. Outcome of cryopreserved-thawed embryo transfer in the GnRH agonist versus antagonist protocol. Iran J Reprod Med. 2012;10(4):297-302.

13. Parmar T, Gadkar-Sable S, Savardekar L, et al. Protein profiling of human endometrial tissues in the midsecretory and proliferative phases of the menstrual cycle. Fertil Steril. 2009;92(3):1091-1103. doi:10.1016/j.fertnstert.2008.07.1734

14. Hernandez ER. Embryo implantation and GnRH antagonists: embryo implantation: the Rubicon for GnRH antagonists. Hum Reprod. 2000;15(6):1211-1216. doi:10.1093/humrep/15.6.1211

15. Rackow BW, Kliman HJ, Taylor HS. GnRH antagonists may affect endometrial receptivity. Fertil Steril. 2008;89(5):1234-1239. doi:10.1016/j.fertnstert.2007.02.059

16. Altmae S, Esteban FJ, Stavreus-Evers A, et al. Guidelines for the design, analysis and interpretation of 'omics' data: focus on human endometrium. Hum Reprod Update. 2014;20(1):12-28. doi:10.1093/humupd/dmt048

17. Prior JC, Naess M, Langhammer A, Forsmo S. Ovulation prevalence in women with spontaneous normal-length menstrual cycles a population-based cohort from HUNT3, Norway. PLoS One. 2015;10(8):e0134473. doi:10.1371/journal.pone.0134473
18. Wisniewski JR, Vildhede A, Noren A, Artursson P. In-depth quantitative analysis and comparison of the human hepatocyte and hepatoma cell line HepG2 proteomes. J Proteomics. 2016;136:234-247. doi:10.1016/j.jprot.2016.01.016

19. Nielsen PA, Olsen JV, Podtelejnikov AV, Andersen JR, Mann M, Wisniewski JR. Proteomic mapping of brain plasma membrane proteins. Mol Cell Proteomics. 2005;4(4):402-408. doi:10.1074/ mcp.T500002-MCP200

20. Cox J, Mann M. MaxQuant enables high peptide identification rates, individualized p.p.b.-range mass accuracies and proteome-wide protein quantification. Nat Biotechnol. 2008;26(12):1367-1372. doi:10.1038/ nbt. 1511

21. Cox J, Neuhauser N, Michalski A, Scheltema RA, Olsen JV, Mann M. Andromeda: a peptide search engine integrated into the MaxQuant environment. J Proteome Res. 2011;10(4):1794-1805. doi:10.1021/pr101065j

22. Choi H, Nesvizhskii AI. False discovery rates and related statistical concepts in mass spectrometry-based proteomics. J Proteome Res. 2008;7(1):47-50. doi:10.1021/pr700747q

23. Cox J, Hein MY, Luber CA, Paron I, Nagaraj N, Mann M. Accurate proteome-wide label-free quantification by delayed normalization and maximal peptide ratio extraction, termed MaxLFQ. Mol Cell Proteomics. 2014;13(9):2513-2526. doi:10.1074/mcp. M113.031591

24. Gentleman R, Carey V, Huber W, Irizarry R, Dudoit S, eds. Bioinformatics and Computational Biology Solutions Using $R$ and Bioconductor, Statistics for Biology and Health. New York: Springer; 2005.

25. Huang Da W, Sherman BT, Lempicki RA. Bioinformatics enrichment tools: paths toward the comprehensive functional analysis of large gene lists. Nucleic Acids Res. 2009;37(1):1-13. doi:10.1093/nar/ gkn923

26. Chen Q, Zhang A, Yu F, et al. Label-free proteomics uncovers energy metabolism and focal adhesion regulations responsive for endometrium receptivity. J Proteome Res. 2015;14(4):1831-1842. doi:10.1021/acs.jproteome.5b00038

27. Lédée N, Prat-Ellenberg L, Chevrier L, et al. Uterine immune profiling for increasing live birth rate: A one-to-one matched cohort study. J Reprod Immunol. 2017;119:23-30. doi:10.1016/j. jri.2016.11.007

28. Hannan NJ, Evans J, Salamonsen LA. Alternate roles for immune regulators: establishing endometrial receptivity for implantation. Expert Rev Clin Immunol. 2011;7(6):789-802. doi:10.1586/ eci. 11.65

29. Kitaya K, Yasuo T, Tada Y, et al. Unusual inflammation in gynecologic pathology associated with defective endometrial receptivity. Histol Histopathol. 2014;29(9):1113-1127.

30. Reissmann T, Schally AV, Bouchard P, Riethmiiller H, Engel J. The LHRH antagonist cetrorelix: a review. Hum Reprod Update. 2000;6 (4):322-331. doi:10.1093/humupd/6.4.322

31. Ramakrishnappa N, Rajamahendran R, Lin YM, Leung PC. GnRH in non-hypothalamic reproductive tissues. Anim Reprod Sci. 2005;88 (1-2):95-113. doi:10.1016/j.anireprosci.2005.05.009

32. Impicciatore GG, Tiboni GM. Extrapituitary actions of GnRH antagonists: prospects for invitro fertilization programs. Curr Pharm Des. 2012;18(3):264-269. doi:10.2174/ 138161212799040358

33. Gurka G, Rocklin RE. Reproductive immunology. JAMA. 1987;258 (20):2983-2987. doi:10.1001/jama.1987.03400200189024

34. Whang DH, Kim SH, Park MH, Choi YM. Association of HLA-A, $\mathrm{B}$ antigens with susceptibility to advanced endometriosis in Koreans. Korean J Lab Med. 2008;28(2):118-123. doi:10.3343/ kjlm.2008.28.2.118 
35. Kitawaki J, Obayashi H, Kado N, et al. Association of HLA class I and class II alleles with susceptibility to endometriosis. Hum Immunol. 2002;63(11):1033-1038. doi:10.1016/S0198-8859(02) 00438-X

36. Sayegh RA, Tao XJ, Leykin L, Isaacson KB. Endometrial alpha-2 macroglobulin; localization by in situ hybridization and effect on mouse embryo development in vitro. J Clin Endocrinol Metab. 1997;82(12):4189-4195.
37. Sayegh R, Awwad JT, Maxwell C, Lessey B, Isaacson K. Alpha 2-macroglobulin production by the human endometrium. J Clin Endocrinol Metab. 1995;80(3):1021-1026.

38. Macklon NS, van der Gaast MH, Hamilton A, Fauser BC, Giudice LC. The impact of ovarian stimulation with recombinant FSH in combination with GnRH antagonist on the endometrial transcriptome in the window of implantation. Reprod Sci. 2008;15 (4):357-365. doi:10.1177/1933719107311781

\section{Publish your work in this journal}

Drug Design, Development and Therapy is an international, peerreviewed open-access journal that spans the spectrum of drug design and development through to clinical applications. Clinical outcomes, patient safety, and programs for the development and effective, safe, and sustained use of medicines are a feature of the journal, which has also been accepted for indexing on PubMed Central. The manuscript management system is completely online and includes a very quick and fair peer-review system, which is all easy to use. Visit http://www. dovepress.com/testimonials.php to read real quotes from published authors. 